\title{
EL TRAZADO DE LA CIUDAD COMO UNA VARIABLE PARA LA GENERACIÓN DE RUTAS TURÍSTICAS URBANAS SIGNIFICATIVAS. LOS ANDES, UN ANÁLISIS TOPOLÓGICO DE SU CENTRO HISTÓRICO
}

\author{
Felipe Lazo-Mella, Arquitecto \\ felipelazo@cityp.org \\ Centro de Investigación en Turismo y Patrimonio de la Región de Valparaíso, Chile.
}

\begin{abstract}
Abel Cortéz-Ahumada, Historiador
abelcortez@cityp.org

Centro de Investigación en Turismo y Patrimonio de la Región de Valparaíso, Chile.
\end{abstract}

\section{RESUMEN}

La teoría de "Space Syntax" ha probado la relación que existe entre la configuración espacial y la tendencia de uso de sus componentes. Para ello desarrolla herramientas de software que son capaces de entregar valores cuantitativos y cualitativos topológicos de un caso a través de dos tipos de análisis y gráficos: axial y de visibilidad. Este estudio utiliza estas herramientas para evaluar las características topológicas del damero central de Los Andes a través de tres representaciones planimétricas (1890, 1934, 2015 con imagen digital), junto a la revisión de su contexto histórico, con dos objetivos: 1) individualizar componentes significativos del trazado y posibles cambios en los valores que se pudiesen producir por la expansión de la ciudad y sus conexiones con el centro urbano, y, 2) probar la utilidad de esta información para la creación de rutas turísticas urbanas significativas. Como resultado se obtiene que el centro urbano de Los Andes se ve fuertemente afectado por la expansión de la ciudad, pasando de tener una conectividad e integración marcada por los ejes centrales oriente-poniente a una conectividad e integración norte-sur, cuestiones que se correlacionan tanto con la forma del patrimonio urbano protegido y como con fotografías georreferenciadas alojadas en las principales plataformas de mapeo. Junto a esto, su inteligibilidad se reduce a través de los años, haciendo su navegación menos intuitiva. Concluimos con dos propuestas de rutas que consideran la imagen compartida como nodos de atracción visual, conectividad, integración e inteligibilidad.

Palabaras clave: Space Syntax, turismo, Los Andes, Patrimonio urbano, imagen. 


\title{
CITY LAYOUT AS A VARIABLE FOR MEANINGFUL TOURISTICS ROUTES CREATION. A TOPOLOGICAL ANALYSIS OF LOS ANDES HISTORICAL CENTRE.
}

\author{
Felipe Lazo-Mella, Arquitecto \\ felipelazo@cityp.org
}

Centro de Investigación en Turismo y Patrimonio de la Región de Valparaíso, Chile.

\section{Abel Cortéz-Ahumada, Historiador}

abelcortez@cityp.org

Centro de Investigación en Turismo y Patrimonio de la Región de Valparaíso, Chile.

\begin{abstract}
The theory of "Space Syntax" has proved the relationship between the spatial configuration and the tendency of use of its components. For this, it develops software's tools that can deliver quantitative and qualitative topological values of a study case through two types of analysis and graphics: axial and visibility. We use these tools to evaluate the topological characteristics of the central area of Los Andes city through three planimetric representations (1890, 1934, 2015 with digital image). By doing this, we aim to achieve two objectives: 1) individualize significant components changes in the layout and possible shifts in the values in the connections with the urban center, and 2) prove the usefulness of this information for the creation of significant urban tourist routes.
\end{abstract}

As a result, we obtain that the historic center of Los Andes is strongly affected by the expansion of the city. From having a connectivity and integration marked by the central east-west axis to a north-south connectivity and integration. This change correlates both with the protected urban heritage form and with georeferenced users photographs housed on the main online mapping platforms. Along with this, we observe that the city center intelligibility diminishes over the years, making its navigation less intuitive.

We conclude with two proposals of routes that consider the shared image as nodes of visual attraction, connectivity, integration, and intelligibility.

Key words: Space Sintax, tourism, Los Andes, urban heritage, image. 


\section{1.- INTRODUCCIÓN}

Es el turismo en masa como parte de la industrialización que inicia en la segunda mitad del siglo XIX promociona los destinos de sol y playa. Sin embargo, el turismo urbano tiene un origen anterior, junto con el paradigma del viaje turístico cultural que durante el Renacimiento europeo -siglos XV XVIII- recibió el nombre de Grand Tour. Este era llevado a cabo por jóvenes aristócratas y era parte de su formación. Los destinos de estos tours eran centros urbanos. Dentro de los más destacados se encontraban Roma y específicamente las ruinas del foro romano, un referente cultural para los humanistas. La dificultad que implicaba para la época trasladarse a estos centros urbanos creó un desprecio por los espacios intermedios y la naturaleza y en contraste una glorificación de las ciudades donde se encontraban comodidades, cultura y diversión.

Actualmente, el turismo ha evolucionado $y$ es multidimensional; el turismo en masa sigue existiendo, pero se mezcla con un turismo local y de experiencias. Destinos de naturaleza conviven con destinos urbanos.

El espacio urbano es una construcción de variadas dimensiones: física, visual, social, histórica, representativa, etc. El interés en el turismo urbano se genera por una mezcla de estos componentes, en distintos grados de equilibrio, para generar un relato coherente -de significado tanto local como foráneo- asociado al lugar. Sin embargo, ejercicios de este tipo - generar rutas turísticas urbanas, por ejemplo- han tenido dispares resultados. Esto se debe a que uno de los principales componentes que unifican y potencian las propiedades intrínsecas de los espacios no es conocido, considerado o abordado de una manera efectiva. Este componente es la dimensión del tiempo histórico; “(...) Si observáramos detenidamente la continuidad de la vida urbana, ello nos permitiría darnos cuenta de cuán profunda es la carencia de la dimensión del tiempo histórico en nuestra percepción actual" (Márquez, 2013: 52). En este sentido, el patrimonio urbano tiene variadas acepciones relacionadas con el espacio físico construido y con el significado cultural y social que la ciudadanía y el visitante le dotan a través de su experiencia de uso en el tiempo.

Una manera de abordar la generación de rutas turísticas efectivas y significativas, es a través del estudio del espacio como una serie de conexiones. Esto permite visualizar relaciones tendenciales entre el espacio físico y su uso, donde el ejercicio comparativo de distintos periodos entrega una interpretación de las características y dimensiones de los lugares y de sus transformaciones.

En la evidente fragmentación de la arquitectura y la estructura urbanas, se promueven tours urbanos continuos y pretendidamente inteligibles, lo que, sin mediar una propuesta de interpretación de las transformaciones históricas de la ciudad, podría caer en falseamiento 
o invisibilización de los procesos urbanos (acumulativos y siempre conflictivos).

Los análisis topológicos cobran vital importancia en el espacio urbano para determinar, a través de su uso en diversas épocas, el rescate de un imaginario colectivo representativo de esos procesos, interpretaciones y estudios que se potencian por las posibilidades que entregan las Nuevas Tecnologías de la Comunicación y su vinculación a la promoción turística cultural o patrimonial.

\subsection{El caso de Estudio}

El caso que nos ocupa, la ciudad de Los Andes, se funda en 1791 con el objetivo de servir como núcleo urbano articulador del tráfico cordillerano $\mathrm{y}$, secundariamente, como espacio de provisiones para las actividades mineras de Río Colorado.

El centro urbano de Los Andes, por historia y estructura, está delimitado en su fundación, en torno a la cuadrícula de damero de 49 manzanas (siete por costado). Dado que esta estructura perduró sin extensiones formales desde 1791 a 1910, la concentración en torno a la plaza y sus principales vías se reprodujo en el tiempo, acumulando las funciones de provisión de bienes y servicios de mayor cuantía, complejidad y exclusividad, tanto a los habitantes de la ciudad como al espacio rural circundante y dependiente ${ }^{1}$.

El rol de Los Andes, ciudad conectada de manera dependiente al sistema urbano nacional e internacional, cumple la función de irradiar y mediar en la relación de las comunas rurales de su entorno provincial, con los bienes y servicios producidos en los centros metropolitanos nacionales o en las esferas de producción y comercialización globalizada, impactando en la conformación del trazado concreto de la ciudad.

En ese contexto, nuestro estudio pone un enfoque específico en la Calle Esmeralda, que nos permite seguir la evolución de la trama urbana y sus cambios de sentido, desde una de sus principales vías. Nuestros análisis, junto con tematizar la ciudad en su conjunto, irán intercalando focos específicos sobre dicho eje vial.

Dentro del centro urbano, la Calle Esmeralda, desde la fundación de la ciudad, hasta las primeras décadas del siglo $\mathrm{XX}$, fue la principal vía de tránsito del flujo internacional, ya que el camino hacia la cordillera se proyectaba por dicha calle hacia el oriente, flujo que seguía hacia el poniente, donde podía seguir esa dirección o enfilar hacia el sur (Calle Larga, la Cuesta de Chacabuco y finalmente Santiago).

\footnotetext{
$1 \quad$ No obstante, actualmente se han constituido nuevas áreas comerciales al sur-poniente del damero fundacional (el conjunto de mall, tiendas y supermercado denominado Espacio Urbano), persiste aún una estructuración donde el comercio sigue localizado en las principales vías urbanas del centro.
} 
Actualmente la actividad comercial se concentra en el tramo poniente de la Calle Esmeralda, correlativo a los condicionamientos espaciales específicos, como a esa historia de flujos internacionales decimonónicos. Respecto de los focos de atracción que influyen al interior del damero urbano actual, este tramo comercial de Esmeralda se inicia una cuadra y media al oriente de la Plaza, por la reciente instalación del Terminal Intercomunal de Colectivos, recorrido del área comercial sigue desde ese punto hacia el poniente condicionado por el emplazamiento consecutivo del Terminal Intercomunal de microbuses, tiendas comerciales, restaurantes y antiguos hoteles (todos ellos emplazados intermitentemente en toda Esmeralda), Farmacias, Plaza, Bancos, Gobernación, Correo, Municipalidad, Colegio y Supermercado. El comercio en Esmeralda termina en la Av. Santa Teresa, antigua Alameda del Progreso, eje vial que vinculaba con la Calle Larga hacia el sur y, al norte, la Estación de Ferrocarriles (cuando estaba operativa), hoy vía de acceso de buses y camiones a Santiago.

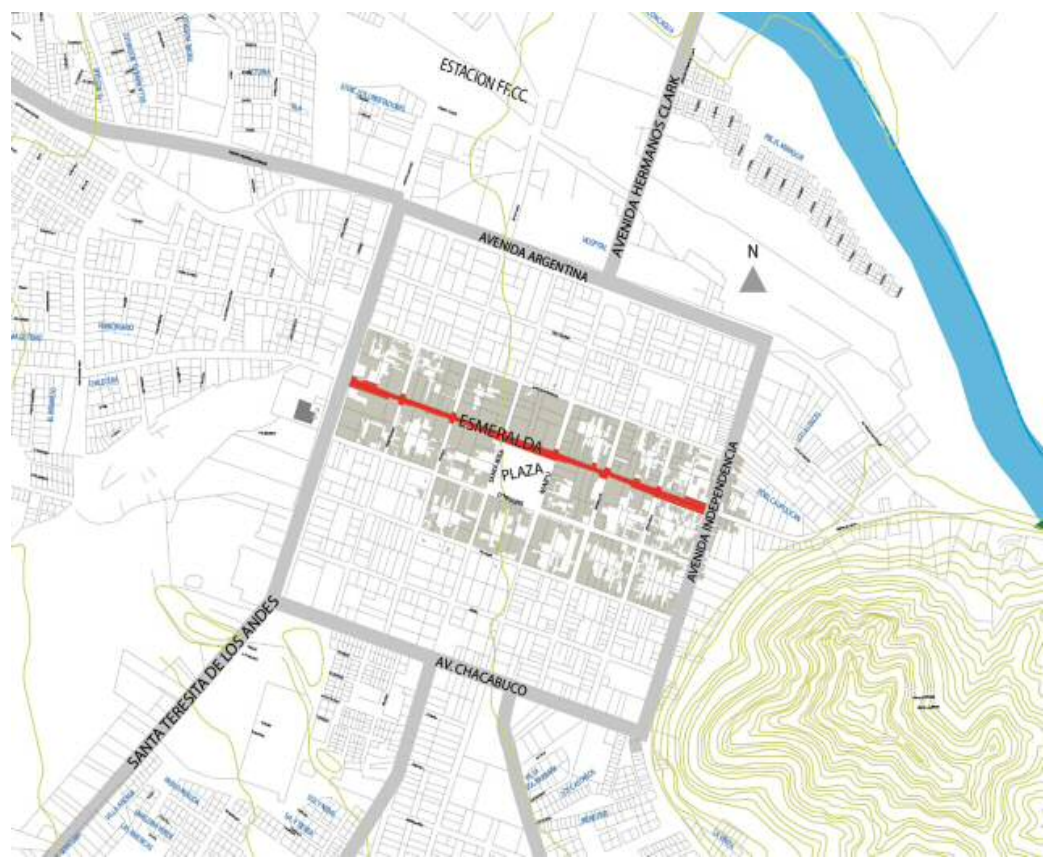

Fig. 1 Plano del estado actual del centro histórico de la ciudad de Los Andes.

Elaborado por K. Barriga y M. Gallardo. 2015. Mapa Base Municipal. 


\section{2.- METODOLOGÍA}

La metodología consiste en una aplicación del análisis topológico del espacio urbano de la teoría de la sintaxis del espacio.

Como objeto de estudio consideramos tres representaciones planimétricas del damero fundacional de una ciudad como Los Andes correspondientes a tres épocas o estados históricos, buscando la correlación expresiva de esa dimensión, en la conformación del patrimonio urbano y la imagen fotográfica de la ciudad compartida en la web, para luego, desde esa correlación, identificar las oportunidades desaprovechadas y proponer alternativas de uso turístico desde la lógica del reconocimiento de recorridos de alta inteligibilidad.

\section{1.- Legibilidad e inteligibilidad como factores clave para ver y entender la trama urbana en su contexto cultural.}

La legibilidad es un término acuñado por Kevin Lynch a mediados del siglo XX en su libro "La imagen de la Ciudad". Es utilizado para establecer el grado de facilidad -o dificultad- con el cual las personas pueden reconocer y entender, de manera lógica, la configuración espacial de un lugar (Lynch, 1998). El análisis de la legibilidad reforzó la importancia de la configuración de los componentes de la ciudad, en un conjunto ordenado que facilite la lectura en el espacio a distintas escalas. El término y los métodos de Lynch, siguen siendo referentes básicos para comenzar a hablar de la imagen de la ciudad, sobre todo, porque considera una creación de la imagen indirectamente a través de la lectura topológica. Dicha lectura analiza las conexiones entre variadas categorías dentro de las cuales se observan las diferentes partes de la ciudad entendidas desde su percepción, siendo algunos de estos elementos: los nodos, las sendas, los límites y los hitos.

De forma similar y más recientemente, el concepto de inteligibilidad es introducido por Bill Hillier (Hillier \& Hanson, 1984). Este concepto se podría entender como una racionalización del concepto de Lynch. La inteligibilidad, como valor de segundo orden, se define como el grado de correlación entre la conectividad (valor local) y la integración (valor global) en un análisis de configuración espacial (Zhang \& Chiradia, 2013) basado en primera instancia en el teorema de grafos y la topología. La hipótesis planteada por Hillier establece que una alta correlación entre conectividad e integración global, asegura que la configuración espacial sea comprensible y predecible para el uso peatonal o vehicular según la escala que se analice.

En consecuencia, tanto la legibilidad de Lynch como la inteligibilidad de Hillier, unen la forma urbana y sus características topológicas con las posibilidades que poseen de ser entendidas y visualizadas mentalmente -el primero de manera perceptiva y el se 
gundo racional. Estas posibilidades, en valores altos, ayudaría al recorrido urbano (y turístico) e incluso a una recepción positiva de dicha configuración urbana (ya que en la práctica se aleja de la sensación desagradable de perdida de orientación). Además, la lectura de estas características de una ciudad, permite entender la tendencia de uso de los espacios y, por consecuencia, el refuerzo de las imágenes referenciales tanto por habitantes como visitantes, con claras implicancias en la promoción turística.

Como análisis práctico y ejercicio racional, se aplica la teoría de Hillier, que al ser posterior, ya incluye los valores perceptivos de la teoría de Lynch. Esta teoría y escuela se denominada space syntax, y fue desarrollada por el Space Syntax Laboratory de la University College of London, posiciones teóricas que se concretizan a través de un software de uso libre, creado específicamente para llevarlas a la práctica; depthmap $\mathrm{X}^{2}$. Este software lo aplicamos sobre tres muestras que son las representaciones planimétricas históricas representativas de tres periodos o estados de la ciudad de Los Andes.

En general, la teoría del space syntax considera dos escalas de valores: locales y globales; y dos tipos de valores: estáticos y dinámicos. Entre el primer grupo se encuentran el valor de conectividad (local) y el de integración (global). El equilibrio entre estos valores, determina el grado de inteligibilidad del conjunto.

El motivo por el cual los valores se agrupan y relacionan de esta manera, dice relación con que la ciudad se entiende como una serie de relaciones entre las escala global y local, tanto del espacio físico como del uso. Una vez obtenidos los valores para cada muestra, se procede a comparar principalmente el valor de inteligibilidad, con el fin de determinar, primero, si existe una coincidencia entre la percepción del lugar en cuanto a que una Calle como Esmeralda -altamente referida y comercial- es topológicamente significativa en el tiempo o si su construcción es meramente cultural, y por otro lado, si es que existe otro orden de calles y espacios con alta tendencia de uso y visibilidad, según los planos históricos y actual analizados.

\section{2.- Muestras: Tres representaciones de la ciudad de Los Andes en el tiempo: 1890,1934 y 2015.}

El método y los presupuestos teóricos descritos se implementan para analizar tres planos de la ciudad de Los Andes. Las ciudades intermedias, como la que estudiamos, poseen núcleos urbanos fundacionales (en este caso tipo damero o cuadricular) que condicionan estructuralmente su desarrollo, tornándose especialmente adecuados para este tipo de estudios.

2 Desarrollado por Tasos Varoudis (2011-2014). En base al trabajo de Alasdair Turner. 
El núcleo urbano, o fundacional, es el más integrador (controlador, etc.) de los espacios de un sistema (Klarqvist, 1993). Su configuración, ya sea que esté totalmente conectado

o desconectado del resto de la ciudad y de qué forma lo está o no lo está, es una de las principales propiedades de la trama urbana, su uso y por consecuencia, de su imagen.

Como núcleo urbano, la grilla cuadriculada de damero, o hipodámica, es el trazado más común en la historia de las ciudades, ya que las líneas rectas facilitaron la defensa de los asentamientos y la distribución equitativa y racional de tierras, objetivos perseguidos en el proyecto de trazado fundacional de una ciudad como la de Los Andes.

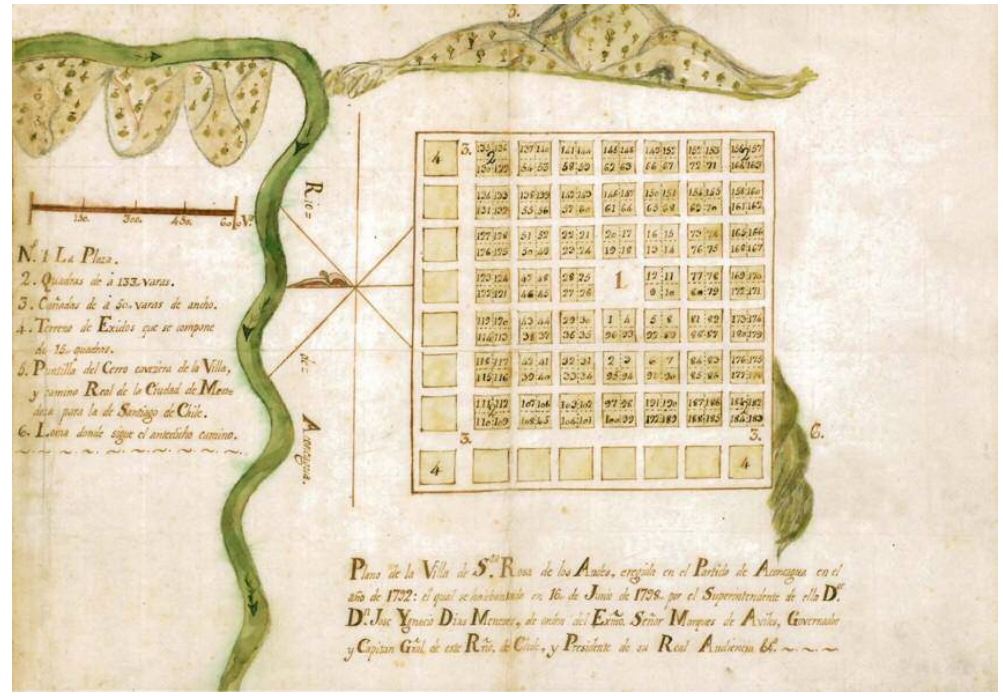

Fig. 2 Plano de la Villa de Santa Rosa de Los Andes. 1798. Fuente: Memoria chilena. Biblioteca Nacional de Chile.

Considerando este trazado del núcleo urbano fundacional como un molde predefinido para el uso de la ciudad, la tendencia de uso de unas calles y espacios por sobre otros graficada en los planos históricos y actual, nos permitirá asociar ciertas imágenes a estos recorridos.

Evaluamos esta función, en base a un tipo de análisis topológico de las transformaciones de la ciudad en la historia, evolución que se puede observar en las representaciones planimétricas en una secuencia cronológica (pasado y presente). Específicamente, las tres representaciones planimétricas -las dos primeras conservadas en los archivos nacionales, la última genérica, al ser originalmente digital- corresponden a los años 1890, 1934 y 2015. Todos los registros fueron 
procesados con el software para establecer sus relaciones topológicas, visuales y axiales y analizados en perspectiva de la historia urbana para sus correlaciones espaciales concretas.

\section{2.- Correlaciones entre análisis topológico y los estudios histórico-urbanos y visuales.}

El objetivo de este estudio es exponer una metodología para leer las característicasconfiguracionales, enlazadasalastendenciasdeusoypercepcióndeloscentros históricos urbanos a través del tiempo, en base a las características que es posible construir desde las representaciones planimétricas del trazado fundacional y su entorno inmediato; tomando como caso la ciudad de Los Andes, Región de Valparaíso, Chile.

Este objetivo se vincula con la necesidad de correlacionar este análisis topológico en dos perspectivas: por un lado, con la estructura urbana del patrimonio protegido de la Zona Típica de la ciudad de Los Andes, y, por otro, con las imágenes compartidas en Googles maps como huellas de la visualidad generada por los habitantes y sobre todo los turistas o visitantes (la demanda). En los resultados, la correlación urbano-topológica será confirmada, ya que la jerarquía relativa que mantiene la Calle Esmeralda se expresa en la constitución de una particular visualidad y espacialidad patrimonial. Características que, proponemos, se pueden constituir en base de una oferta del turismo cultural de experiencias en la ciudad.

Como hipótesis se sostiene que el desarrollo de conexiones preestablecidas en la trama del damero, junto con el carácter de nodo de la ciudad en la vía territorial intercordillerana, ha llevado a establecer lógicas de uso diferenciadas de sus principales calles. En este sentido, la Calle Esmeralda, ha visto comprometida su función original de conector territorial, como efecto de la expansión del área urbana, por lo que la mantención de su jerarquía de uso, por sobre el contexto de la trama del núcleo fundacional, se debe a una mezcla cultural de usos e imaginarios que construyen su valor patrimonial y visual actual, fundados en su gravitación histórica.

\section{RESULTADOS}

Los resultados del estudio se estructuran en dos apartados. El primero dice relación con el análisis topológico de tres planos urbanos de la ciudad de Los Andes, base en el cual se estructurarán los índices de inteligibilidad visual y axial y la conectividad. El segundo apartado, permite realizar un correlato históricoespacial de ese análisis planimétrico, estudiando dos expresiones de esta realidad: la conformación del patrimonio urbano protegido y la imagen digital compartida en la web. 


\subsection{ANÁLISIS TOPOLÓGICO DE PLANOS DE LA CIUDAD DE LOS ANDES.}

Los resultados de nuestro estudio se basan en el análisis topológico de tres planos, el de 1890 , cuando la ciudad ya estaba consolidada en el damero fundacional, manteniendo con pequeños ensanches, dicha estructura; el plano de 1934, cuando la ciudad reflejaba una extensión formal hacia el sur; y, por último, el plano actual de 2015. Estas tres representaciones planimétricas nos permitirán analizar, rastrear y comparar la evolución histórica de la imagen topológica del centro urbano de la ciudad de Los Andes.

\subsubsection{Análisis Plano 1890.}

El plano de 1890 (Fig. 3), es un plano de las condiciones reales que la ciudad presentaba en ese momento. Es un dibujo para imprenta publicado en el libro de Enrique Espinoza, "Jeografía descriptiva de la República de Chile", como forma de ilustrar la descripción de la ciudad de Los Andes. En el plano se referencia la ubicación de las principales instituciones y empresas (industriales y de servicios) tanto en el damero urbano y en las afueras de la ciudad. El límite formal de la ciudad sigue siendo el damero urbano de 49 manzanas, contenidas por cuatro vías, pero ya se observa una expansión hacia el área norte, en convergencia con la ubicación de dos equipamientos estratégicos para la ciudad: la Estación de ferrocarriles del Estado, de 1874, y la Estación del Ferrocarril Trasandino, de fines de 1880 (aunque en proceso de construcción en 1890).

El plano señala también la localización de los principales edificios públicos, hoteles y bancos, los que se emplazan mayoritariamente y de forma jerárquica, en la Calle Esmeralda. Esta misma calle se prolonga, hacia el oriente y el poniente, enlazándose con el macro territorio vial. Al poniente del damero, la Avenida del Progreso, conecta la Calle Larga con la Estación, camino que va hacia Santiago. Se representa la Plaza con un diseño de jardines y paseos, con la idea romántica de llevar el verde a la ciudad y su espacio central.

En el caso específico de los resultados del análisis, la calle presenta un alto número de conexiones comparativas al resto del sistema. Junto a esto, una alta correlación con su valor de integración (por tanto, resulta altamente accesible en comparación al resto de las calles del entorno). En consecuencia, el factor de inteligibilidad axial (Fig. 4 c), como nos muestra la curva de regresión lineal, posee un alto valor para el sistema completo. Esto quiere decir que, dentro de los límites representados en el plano de 1890, este asentamiento es fácilmente recorrible, con una mínima o nula sensación de pérdida y además es reconocible a través de sus principales hitos, ya que existe una correlación entre la disposicióndeestoshitosenelsistemaconlascallesdemásaltaconectividadeintegraciónaxial. 
En cuanto a visibilidad, los resultados son notablemente diferentes (Fig. 4 b). Por un lado, y como es de esperar en una trama ortogonal de damero perfecto, la mayor visibilidad se encuentra en las intersecciones de calles, siendo los puntos de mayor visibilidad comparativa aquellas intersecciones en las esquinas de la Plaza pero, por sobre todo, en las intersecciones de avenidas que encierran el sistema, especialmente la de Avenida el Progreso (Actual Santa Teresa) con la Avenida del Recreo (actual Av. Argentina). Ver Fig. 4 d y e.

Con estos datos, podemos concluir que para el plano de 1890 las principales avenidas concentran una alta visibilidad representativa de la imagen de la ciudad, ya que, además conectan hacia las estaciones de ferrocarriles. En el caso de los hitos -principalmente edificios públicos- se complementan con la tendencia de uso por accesibilidad de las calles que circundan la plaza, dentro de las cuales destaca la calle Esmeralda, de poniente a oriente.

Posibles componentes para una ruta del estado temporal de 1890: Avenida del Progreso, Avenida del Recreo, Estaciones de Ferrocarril, Calle Esmeralda, Iglesia, Hoteles, Edificio de la Gobernación y Correos

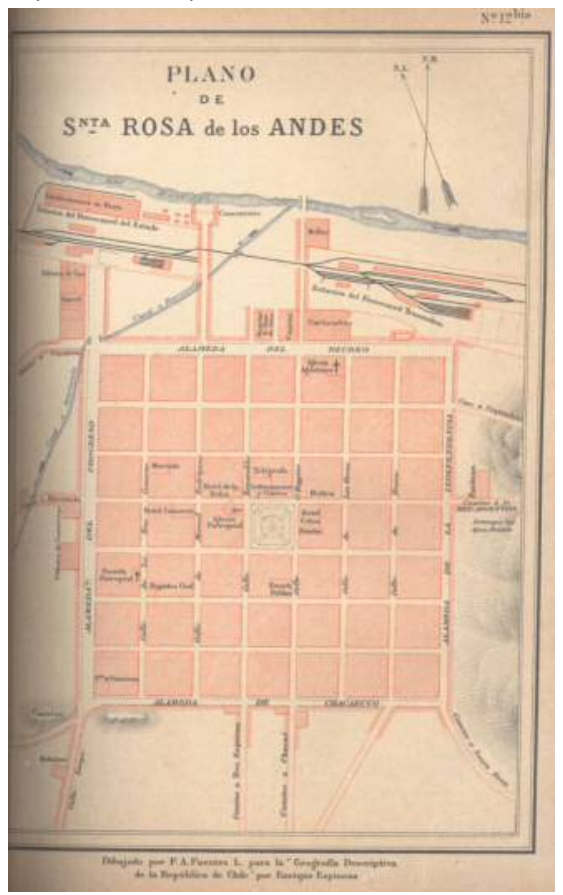

Fig. 3. Plano de Santa Rosa de los Andes, 1890. Dibujado por F.A. Fuentes L. Para la "Geografía Descriptiva de la República de Chile" por Enrique Espinoza. Fuente: Biblioteca Nacional de Chile.. 


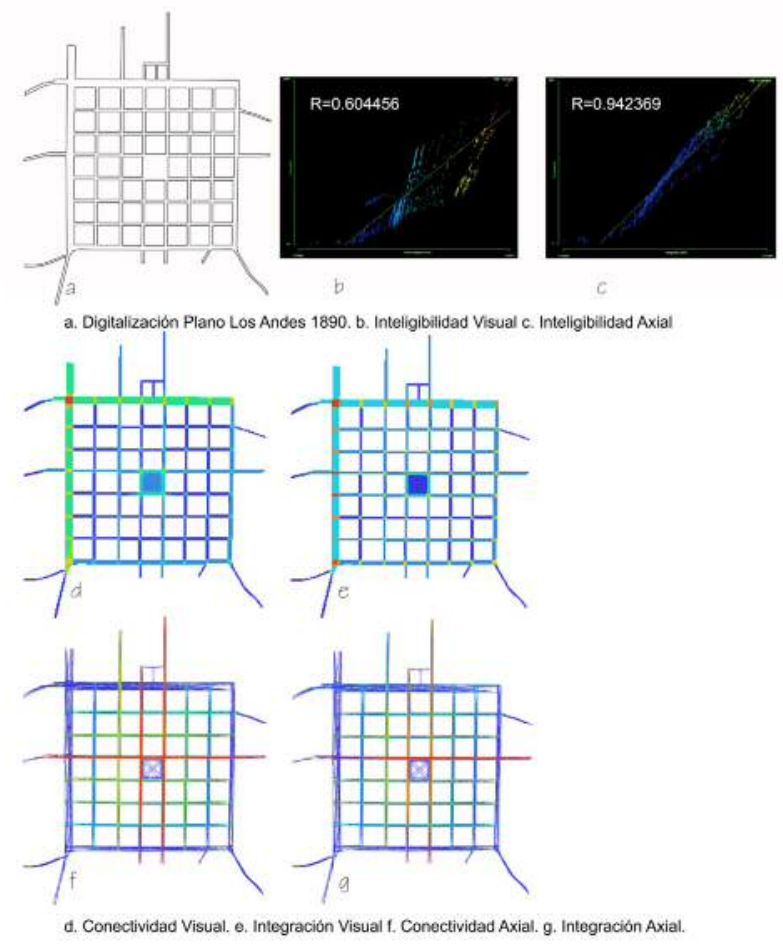

Fig. 4. Configuración espacial de Los Andes en 1890, Digitalización del plano del mismo año. Fuente: Elaboración propia

\subsubsection{Análisis Plano 1934}

El plano de 1934 (Fig. 5), posee manzanas numeradas, cuyo objetivo es la identificación de estas unidades urbanas para la empresa Aseguradora contra incendios, institución que encarga estos planos. La planimetría describe formalmente la división interna de la estructura urbana, pero sin hacer mención a alguna particularidad de edificios como el plano de 1890. La ciudad, en 1934, ya no se restringe únicamente al damero fundacional de 1792 y 1890, sino que desde 1910, hacia el sur, surge la primera extensión formal de la ciudad, representada por la Población Centenario (por los 100 años de la República), prolongando el damero, al menos en sus manzanas centrales.

Unaparticularidad del plano de 1934 es que presenta con línea discontinua la proyección de la calle Membrillar que ha quedado como proyecto inconcluso hasta el presente. Este cambio, 
aunque parezca mínimo, en el análisis se observauna importante diferencia(Marca enFig. 5).

Al realizar el análisis topológico con la representación proyectada del plano de 1934, se observan valores fuertemente dispares entre la inteligibilidad axial con respecto a la visual. Los dos valores han disminuido con respecto a los obtenidos en la representación del periodo anterior (1890). Con la expansión proyectada de la ciudad hacia el sur, las calles que conectan a esta zona, la Plaza y la ahora nombrada avenida "Arjentina" ganan conectividad, especialmente las calles Membrillar y Maipú. Conectividad visual permanece alta en los mismos puntos que en el plano anterior (Fig.6 b), mientras la integración visual se vuelca hacia los puntos norte y sur (Fig.6 c).

Posibles Componentes para una ruta del estado temporal de 1934: Avenida del Progreso, Avenida "Arjentina", Estaciones de Ferrocarril (del estado y Trasandino), Plaza, calleMembrillar, calle Maipú, Edificios públicos, Avenida Chacabuco.

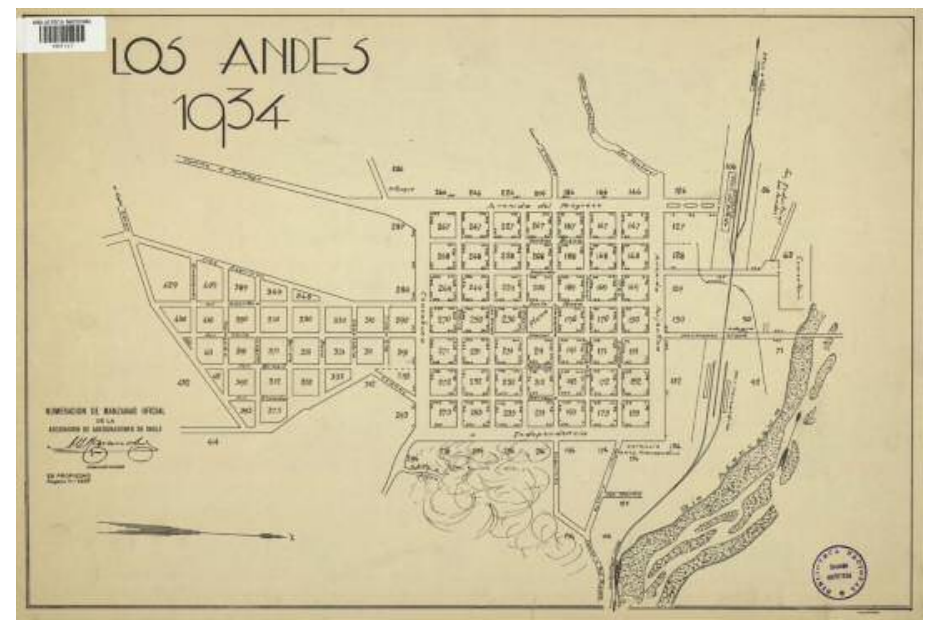

Fig. 5. Plano de la Ciudad de Los Andes. 1934. De la Asociación de Aseguradores de Chile. Fuente: Mapoteca Biblioteca Nacional. Biblioteca Nacional Digital. Se enmarca la proyección hacia el sur de la calle Membrillar, actualmente sin concretar. 
El trazado de la ciudad como una variable para la generación de rutas

Gest. tur, $N^{\circ} 23$, enero - junio 2015, pp 57 - 87

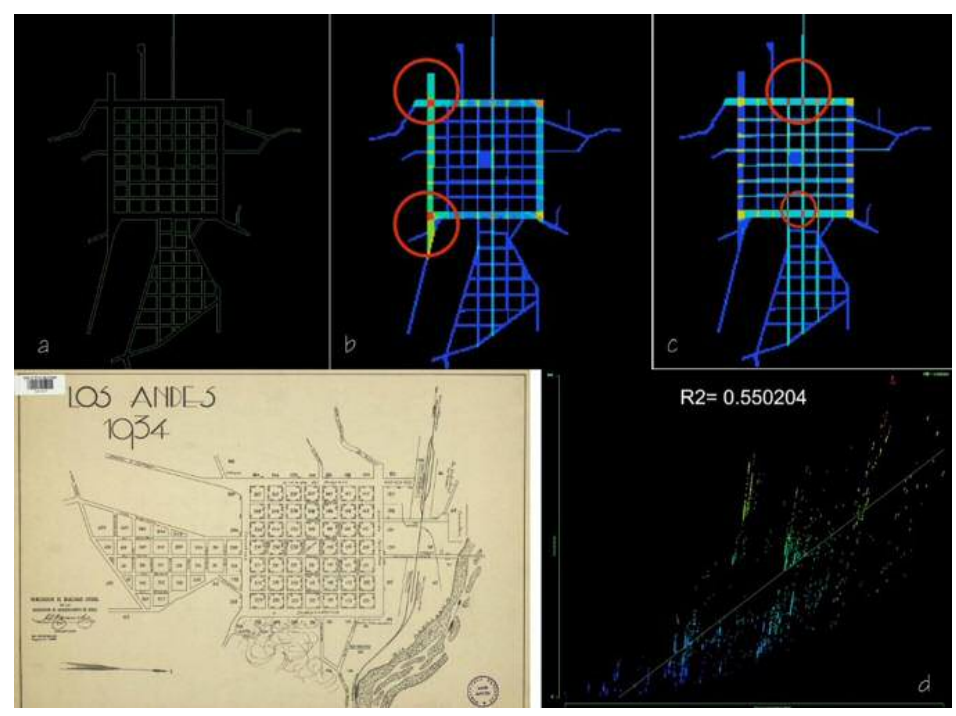

Fig. 6. Plano de Los Andes 1934. Fuente: Biblioteca Nacional. A. Digitalización y rotación. B. Análisis de visibilidad para el valor de Conectividad. Se destacan valores más altos (colores cálidos). C. Análisis de Visibilidad para el valor de Integración. D. Diagrama de dispersión para el valor de Inteligibilidad Visual. Fuente: Elaboración propia.

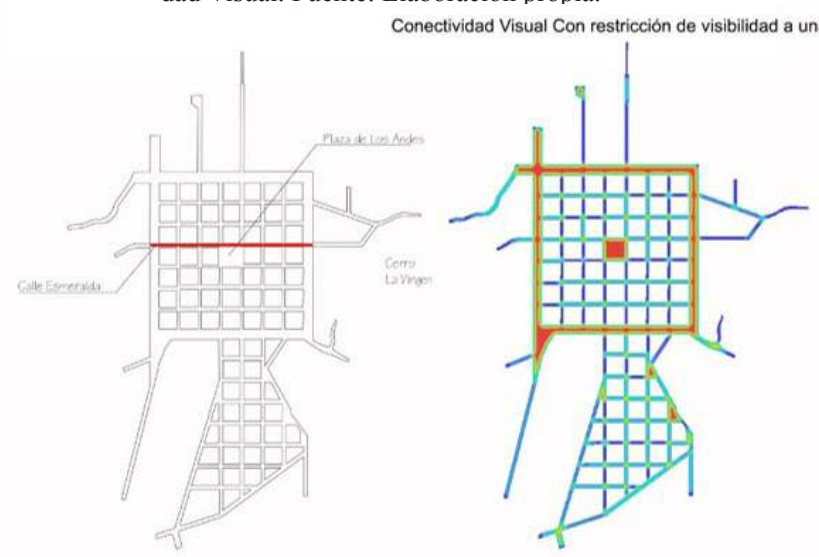

Fig. 7. Configuración espacial de Los Andes en 1934. Digitalización del plano original.

Conectividad Visual restringida a un alcance de visión de una manzana. Se observan micro espacios de alta visibilidad (encuentro de isovistas). Fuente: Elaboración propia. 

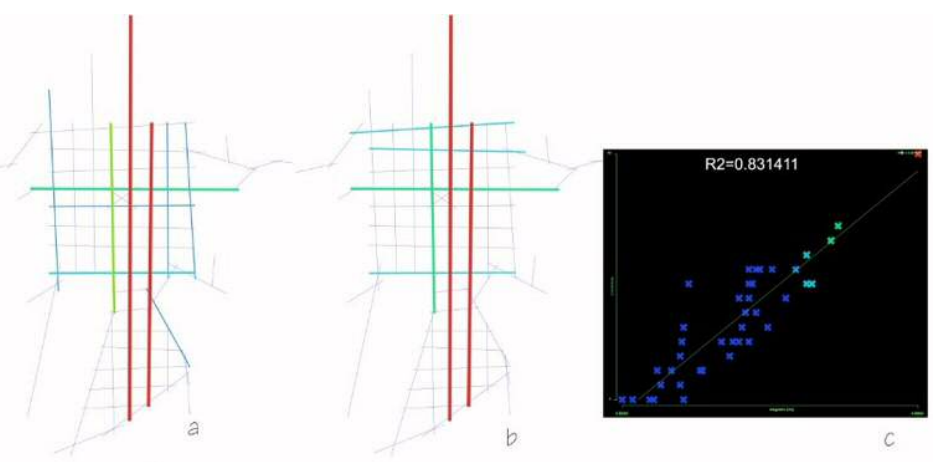

Fig. 8. Los Andes 1934. a. Conectividad Axial. b. Integración Axial. c. Inteligibilidad Axial.

\subsubsection{Análisis Plano 2015.}

El Plano actual, que data del año 2015, grafica el proceso histórico acumulado de expansión de la estructura urbana de Los Andes. El damero fundacional sigue siendo jerárquico en la estructura de la planta de la ciudad, organizando el sentido de la expansión urbana. La primera expansión de la ciudad hacia el sur (1910), que se observa claramente en el plano anterior, demarcó el derrotero de la construcción de conjuntos de viviendas en esa dirección desde 1960. Dicha expansión hacia el sur, y la consolidación de la relación de la ciudad de LosAndes con la comuna de San Esteban, al norte, constituyó a este eje longitudinal como estructural en la morfología y la movilidad urbanas.

Hacia el poniente, conjuntos de viviendas de obreros calificados y sectores medios, marcan a mediados del siglo XX un sentido de expansión significativo, pero menor respecto del sur, siendo la Calle Esmeralda un conector de jerarquía más allá del núcleo fundacional. 


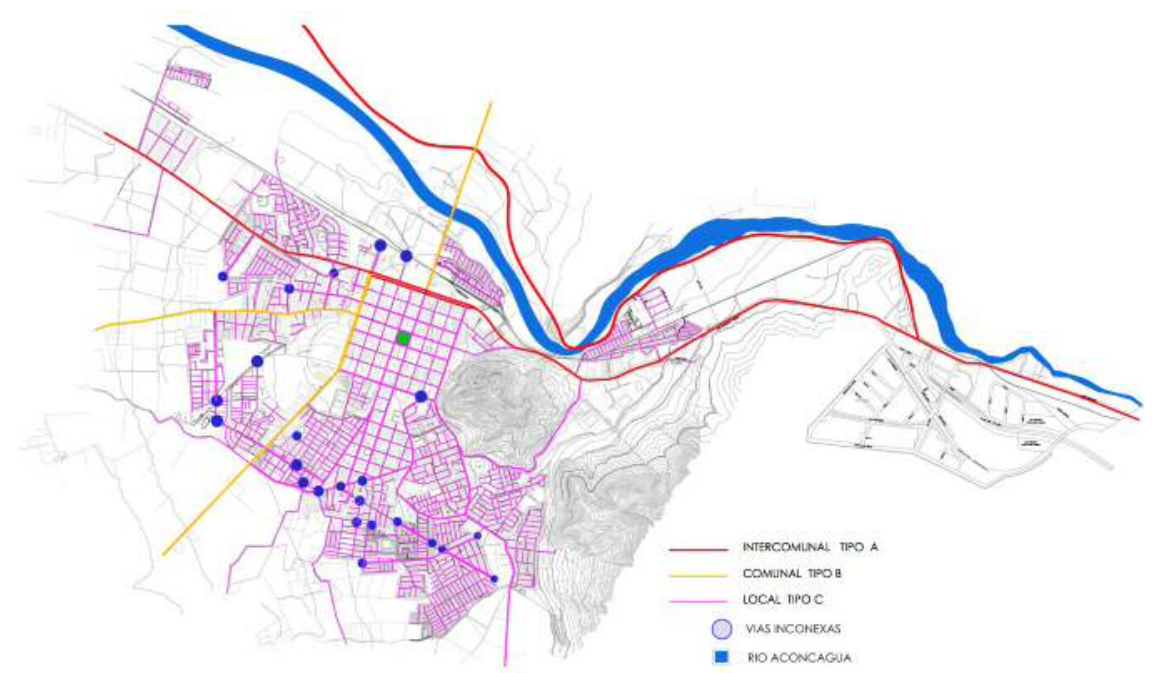

Fig. 9. Plano del estado actual de la ciudad de Los Andes y el carácter de su trazado. Elaborado por K. Barriga y M. Gallardo. 2015 para el Taller de arquitectura de Miguel Prieto Dominguez y Felipe Lazo-Mella de la Escuela de Arquitectura de la Universidad Tecnológica Metropolitana. Mapa Base Municipal.

El análisis topológico del plano actual es indicativo del proceso histórico de expansión en sentido norte-sur, como el gran eje vial de conectividad urbana e interurbana. Dicha vía central, parte en el sur siendo Avenida Chile, en la Población Centenario, luego se denomina Maipú en el damero central, y Avenida Hermanos Clark, hacia el norte (por la cercanía con el antiguo Ferrocarril Trasandino, que dichos hermanos iniciaron).

Ese eje longitudinal en el análisis de conectividad, presenta el mayor valor, puesto que su estructura rectilínea permite conectar distintas estructuras de la ciudad de forma continua, a diferencia de la Calle Esmeralda, que se restringe y curva hacia el norte, y se prolonga en dirección sur-poniente en un trazado sinuoso.

La inteligibilidad axial para este periodo disminuye notablemente. Lo que resulta curioso es cómo la calle Esmeralda sigue teniendo cierto peso en cuanto a conectividad, pero no así en integración.

El análisis topológico del plano actual, propone como ejes de mayor integración la Avenida Chacabuco, que cierra el damero por el sur, junto a la calle Perú, inmediatamente paralela (Fig. 10 b). 
Debido a que las calles con más alta conectividad e integración axial, siguen conectando la plaza, este espacio público mantiene su significación desde este punto de vista, lo que la hace parte importante de un recorrido.

Posibles Componentes para una ruta del estado actual: Avenida Santa Teresa, Iglesia y convento, Ex estación de Ferrocarriles del Estado, Camino a San Esteban, Avenida Argentina, Plaza, calle Maipú, calle Santa Rosa, Edificio de la Gobernación y correos, calle Esmeralda, Avenida Chacabuco, calle Perú.

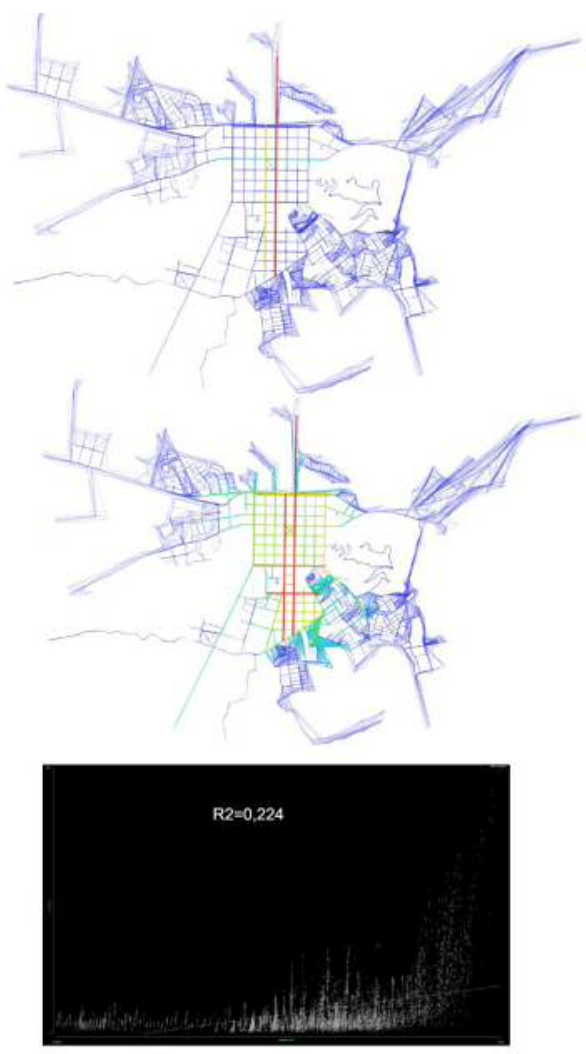

Los Andes a. Mapa Axal. Conectividad. b. Mapa Axial, Integración. c. Grafico de Dispersión. Inteligibilided

Fig. 10. Los Andes. Configuración espacial actual. 
Tabla 1 Resumen comparativo de los valores de segundo orden por año.

\begin{tabular}{|c|c|c|}
\hline Aǹo & Intel. Visual & Intel. Axial \\
\hline 1890 & 0,604456 & 0,942369 \\
\hline 1934 & 0,550204 & 0,831411 \\
\hline 2015 & $\ldots \ldots \ldots-\ldots$ & 0,224 \\
\hline
\end{tabular}

Elaboración propia. El valor máximo (equilibrio completo entre conectividad local e integración global) es igual a 1 . Se destacan los valores más altos.

El trazado de 1890 muestra los valores más altos de inteligibilidad visual. Su inteligibilidad visual es de alrededor de un $60 \%$, lo que se constituye como una limitante del damero $7 \times 7$, que se sostiene en el tiempo y que solo podría ser subsanada con una apertura de espacios (atrios a las fachadas patrimoniales y en conjunto a los espacios de encuentro, por ejemplo) y/o con una modificación menor o mayor del trazado (introducción de diagonales, por ejemplo). La baja inteligibilidad visual es fácilmente apreciable en un recorrido del espacio, en donde la falta de referencias visuales distintivas dentro de las zonas intermedias del damero, resultan en una sensación de pérdida.Esporestoqueelnombredelascallessevuelvemuysignificativojuntoalaseñalética.

Por otro lado, los altos valores de Inteligibilidad axial para todas las muestras, con excepción de la del 2015, da cuenta de la ventaja que provee el trazado ortogonal perfecto en cuanto a conexioneslineales, yaquecongrandestrazosrectosselograconectaryreducirlaprofundidad topológicasignificativamente, loquenosucedeconel trazadoorgánicoenestetipodeanálisis.

\subsection{4.- Principales resultados y reflexiones del análisis topológico de los tres planos.}

Se visualiza una expansión de la estructura urbana hacia el sur y poniente. Esto es consecuente con el desarrollo de la ciudad y con la contención que significa el Cerro Isla de la Virgen al oriente y el Río Aconcagua por el norte (Cortez, 2012). La ciudad, al expandirse, lo hace según diversas capas histórico-constructivas, lo que no permitió prolongar la organización racional del damero fundacional (cuadricular), sino que lo hizo en agregaciones disímiles y en diversas direcciones (según la proposición de los proyectos habitacionales o la trama rural previa). De esta forma, el trazado del núcleo fundacional cuadricular, se transforma en una enmarañada red vial, lo que hace que su conectividad e inteligibilidad se reduzca con el tiempo. Este proceso culmina en que las condiciones de inteligibilidad de la ciudad se hagan difusas, es decir, bajan las posibilidades de que las vías conduzcan, de manera lógica, a otras vías y a lugares públicos centrales. 
La urbe -como conjunto- se hace más difusa y menos conectada internamente, pero, su centro fundacional, visto ahora como unidad al interior de la ciudad, cobra mayor relevancia como núcleo con mayor nivel de inteligibilidad y conectividad. Este núcleo central, por la acumulación de instituciones, edilicia pública y patrimonio arquitectónico, le permite mantener su jerarquía en la estructura interna de la ciudad, recibiendo el mayor nivel de flujo y visualidad, tanto en sus vías centrales, como en los ejes exteriores. Como resultado de los análisis topológicos obtuvimos que los valores más altos de conectividad (número de conexiones efectivas) e integración (profundidad o distancia topológica promedio menor) se concentran en las calles que encierran la plaza (Esmeralda y Maipú) y las dos principales avenidas que encierran el damerode 7x7(Av. SantaTeresayAv.Argentina).Patróncoincidenteenlosplanosanalizados.

Respecto de las vías centrales, que encierran la plaza, y manteniendo el foco en Esmeralda, esta vía pasa en los tres planos de tener la mayor jerarquía topológica (1890) a una progresiva pérdida de relevancia en la estructura interna (relevancia que adquirirá el eje norte-sur por su trazado longitudinal rectilíneo). No obstante haber perdido en la actualidad su función como conector internacional, en el sentido oriente-poniente, mantiene su relevancia en la estructura topológica y urbana de la ciudad como vía de gravitación histórica y espacial.

Este estudio topológico, por su forma esquemática de análisis espacial planimétrico, donde se codifican y potencian ejes rectilíneos, nos da como resultado que Esmeralda pierde relevancia; pero, si se considera su trazado como conector vial intercomunal hacia el poniente y la localización de los principales edificios públicos de carácter comunal y provincial, tenemos que mantiene su importancia perceptiva. Esta calle, al contar con los edificios emblemáticos y de poder local, como por la aglomeración comercial y de transporte, mantiene su jerarquía, recibiendo un flujo y una visibilidad de importancia, que se verá graficada en una visualización turística indirecta, vía captura y socialización de fotografías tomadas en ella. Además, como veremos en el apartado siguiente, en su faja se concentra la arquitectura de mayor valor patrimonial, situación reconocida en el polígono de la Zona Típica.

En relación a los ejes exteriores del centro urbano, Av. Santa Teresa y Av. Argentina, se constituyen en vías de gran visibilidad y conectividad, tanto a nivel de las representaciones planimétricas, como por el desarrollo urbano concreto. En los planos, su jerarquía crece, ya que son las avenidas con mayores anchos y con conectividad estructural, lo que aumenta sus niveles de visibilidad y conectividad axial. En la realidad concreta, Av. Santa Teresa, conecta hacia el sur (en dirección a la expansión urbana, Calle Larga y Santiago) y el norte (San Esteban y el flujo internacional oriente-poniente), instalándolas como ejes de traspaso insoslayables del 
plano urbano, pero aún subvalorados como vialidad de referencialidad turística y visual.

\section{2.- CORRELATO URBANO DEL ANÁLISIS TOPOLÓGICO DE LOS ANDES. LA CALLE ESMERALDA Y SU IMAGEN.}

Acontinuación, se presenta la correlación entre las dinámicas urbanas concretas y los análisis topológicos, paragraficarlaimportanciadelcentrofundacionalensuconjunto, ydelejevialde Esmeralda. Ello, nos permitirá a continuación, identificar las oportunidades desaprovechadas para el turismo y proponer algunas alternativas de usos para un turismo cultural urbano.

\subsection{1) La Zona Típica de Los Andes y su imagen patrimonial.}

La densidad histórico-espacial del centro fundacional en general, y de la Calle Esmeralda, en particular, se ve reflejado en una arquitectura consolidada en la ciudad en el periodo que va entre 1890-1940, medio siglo en que la ciudad refacciona viviendas, construye edificios públicos, hermosea su plaza, gracias al incremento del erario nacional por los impuestos del salitre, y a nivel local por el dinamismo económico que impulsa la habilitación del Ferrocarril Trasandino.

En esa época, la ciudad va produciendo una imagen donde el neoclásico y el art decó son sus principales esquemas estilísticos, asociados a las áreas centrales del damero fundacional, siendo la Calle Esmeralda, por su jerarquía interna en la trama urbana, la principal depositaria de estos avances constructivos y estilísticos en edificios públicos y residencias privadas.

Esta situación queda relevada y reconocida en la normativa urbana patrimonial que la protege. Por Decreto Exento $\mathrm{N}^{\circ}$ 9, de enero del 2000, por Ley 17.288, se le otorga la condición de Monumento Nacional al edificio de la Gobernación de Los Andes (frente a la Plaza por Esmeralda), edificio emblemático de la espacialidad y visualidad de la ciudad, y, aún más significativo, por el mismo decreto, se le da la condición de Zona Típica a un polígono del Centro Histórico de Los Andes.

La Zona Típica (Fig. 11) no protege el conjunto del damero fundacional, sino un área del núcleo central. Es una forma irregular, cuya principal extensión se da precisamente en Calle Esmeralda, donde se emplaza el principal agrupamiento continuo de construcciones con mayor valor histórico y arquitectónico, y donde se dan las principales alturas. Es decir, los valores urbanos y arquitectónicos más significativos, de mayor extensión en términos de la protección del conjunto urbano, es precisamente en esta vía. En las dinámicas concretas de la ciudad, en la acumulación histórica de la 
arquitectura y la espacialidad, y en el imaginario visual posibilitado, Esmeralda sigue manteniendo una referencialidad indiscutible, que se expresa en la protección legal de su patrimonio arquitectónico y en la construcción de la imagen digital.

Calle Esmeralda, y el conjunto patrimonial del cual forma parte, contienen una arquitectura de valor urbano y arquitectónico, característico de una ciudad de provincia que ostentó cierto desarrollo a fines del siglo XIX y primera mitad del siglo XX. Los edificios de mayor altura e importancia arquitectónica, como la Gobernación Provincial, el Edificio Consistorial de la Municipalidad, los antiguos edificios de los Hoteles Continental y Plaza (hoy devenidos en espacios de tiendas), el Templo Parroquial, y edificios privados (residenciales y comerciales) se emplazaron y acumularon históricamente en Calle Esmeralda, otorgándole la mayor densidad de valor patrimonial.

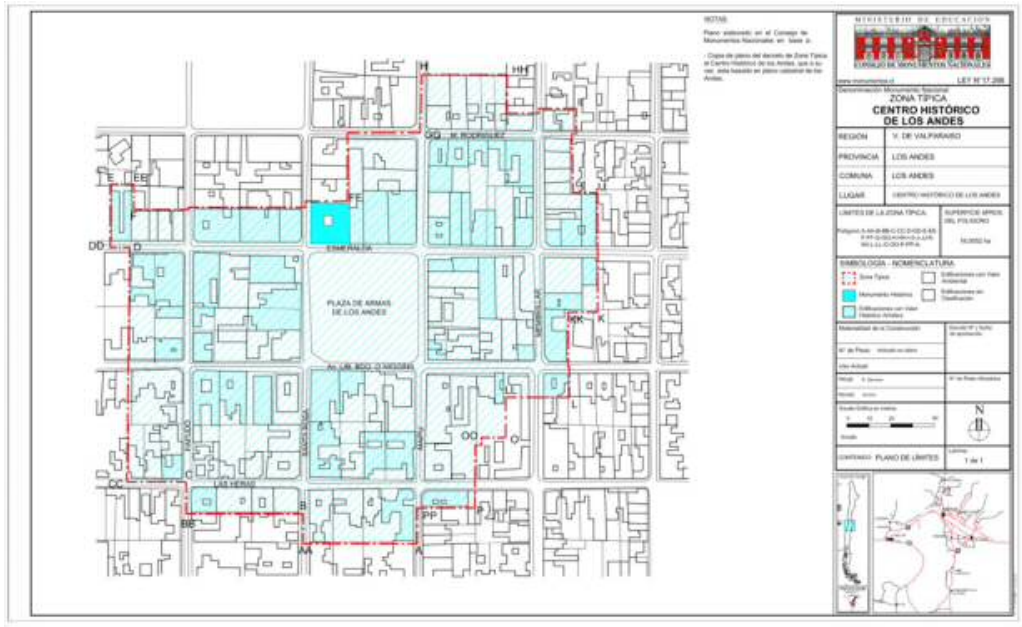

Fig. 11. Plano del Consejo de Monumentos Nacionales que delimita gráficamente la zona típica, los monumentos históricos y las Edificaciones con Valor Histórico Artístico. Fuente: www.monumentos.cl

La Zona Típica, como polígono en el núcleo del centro fundacional, posee los mismos valores que dicho centro obtiene en el análisis topológico. Entre ellos, el principal valor es la inteligibilidad, como condición que hace entendible la ciudad en sus flujos internos, valor que posibilitaría recorridos urbanos para apreciar la espacialidad y la arquitectura que como conjunto constituyen el patrimonio urbano local.

El patrimonio material protegido por la Zona Típica se podría potenciar en su valoración social (por habitantes y turistas) al aprovechar su condición de área urbana inteligible, entendible en su recorrido. En ese trecho, la ciudad se transfor 
ma en un escenario privilegiado para recorrer la historia urbana, lo que, sumado a la alta visibilidad de la Plaza, su principal espacio público central, daría elementos para plantear rutas turísticas que aprovechen dichas condiciones del núcleo.

\subsection{2) La imagen -digital- compartida.}

Según (Caro, Luque, \& Zayas, 2015) las nuevas tecnologías de la información y las comunicaciones "(...)han revolucionado la forma de promocionar e interpretar el patrimonio cultural en el mundo del turismo". El turismo de intereses especiales como es el turismo cultural urbano contemporáneo debe tener en cuenta que los nuevos turistas son consumidores y generadores de información en los destinos a través de blogs, redes sociales y por sobre todo a través de plataformas en donde se comparten fotografías de los lugares y sus experiencias asociadas.

He aquí la relevancia del análisis topológico correlacionarlo con la producción de las imágenes que sobre la ciudad se comparten en plataformas georreferenciados de la web.

Según los más recientes estudios de popularidad y uso de redes sociales las plataformas más utilizadas de mayor a menor a nivel mundial son: Facebook, Youtube, Instagram, Twitter, Reddit, Vine, Ask.fm, Tumblr, Flickr, Goole+, Linkedin, Pinterest (Hsu, Lee, \& Zhang, 2002)(«Top 15 Most Popular Social Networking Sites (and 10 Apps!) - DreamGrow», s. f.). De todas estas las únicas específicas de fotografía son Flickr y Pinterest. En el primer caso una búsqueda general con los tags Los Andes Chile, da como resultado una cuadricula de fotos ordenadas por relevancia como la que vemos en la Fig. 13

De las primeras 25 fotos presentadas en la búsqueda de Flickr, doce se relacionan directa o indirectamente con el centro urbano de la ciudad de Los Andes, siete muestran directamente la plaza central, dos hacen referencia histórica, ocho muestran actividades o atractivos del entorno rural y por último dos muestran curiosamente irrupciones de infraestructura en la imagen urbana (cables de alumbrado público y antenas de telefonía celular). Es importante notar también que dos de estas fotografías muestran directamente el centro urbano y su trazado de calles. Si realizamos otra búsqueda, pero con términos sino directamente en el mapa (fig. 14), las fotografías georreferenciadas de la zona vemos claramente como las fotografías se concentran el centro del damero donde está la plaza, específicamente en la esquina nor-poniente donde se encuentran sus construcciones más emblemáticas: el edificio de la gobernación y la iglesia. No podemos dejar de notar la coincidencia que existe entre la delimitación de la zona típica (fig 12) y la geolocalización de las imágenes compartidas más relevantes. 


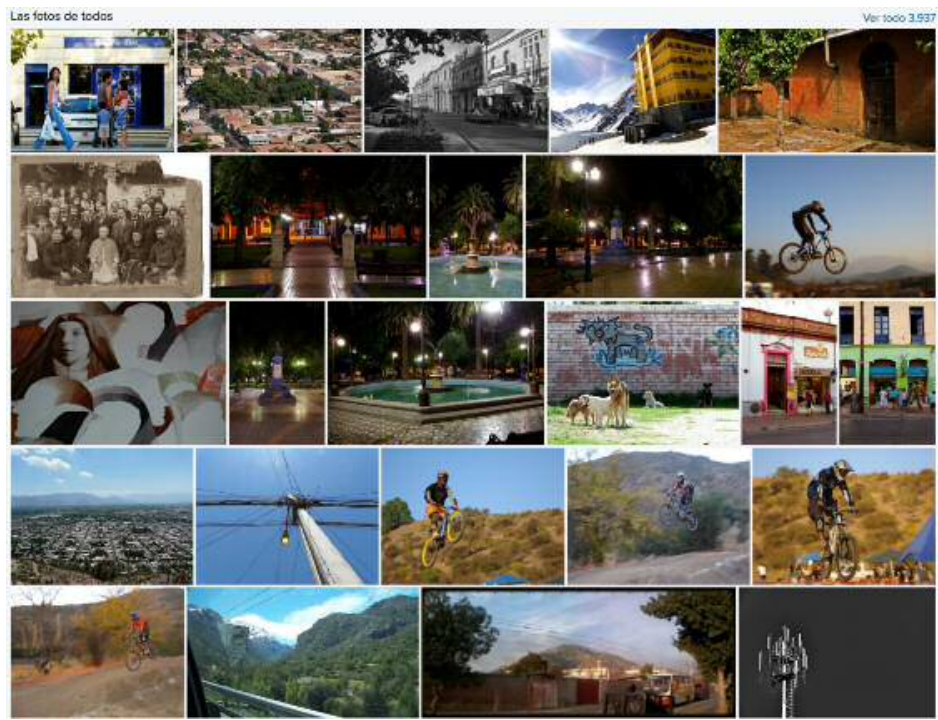

Fig. 12 Flickr, busqueda "Los Andes Chile" por relevancia. Fuente: flickr.com. Consultado en Diciembre de 2016

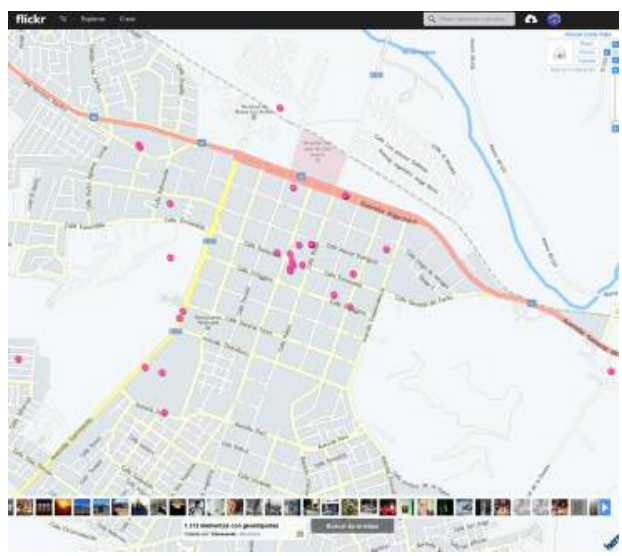

Fig. 13 Fuente: flickr.com. Consultado en Diciembre de 2016

Dentro de las principales plataformas de mapas digitales enlazadas a fotografías georreferenciadas se encuentran google map y google earth. Estas plataformas visualizan las fotografías localizadas desde Panoramio. A pesar de que Panoramio dejó de funcionar el 4 de noviembre de 2016, sigue siendo un repositorio de imágenes de gran valor, ya que han sido subidas y geolocalizadas por los propios usuarios (en su mayoría turistas y visitantes que dejan huellas de su paso), según sus propias experiencias e intereses. 
Estás imágenes se encuentran georreferenciadas e indicadas tanto en las búsquedas directas con el término Los Andes, como con la búsqueda indirectas en el navegador de Google Maps, Panoramio ${ }^{3}$.

Las fotografías más populares de la zona en esta plataforma, desde el nivel de las escalas nos dan cuenta de diversas situaciones. Si se va de la escala macro, observando la ciudad inserta y relacionada con el territorio del Valle de Aconcagua, las fotografías más populares compartidas se vinculan principalmente atemas de naturaleza y ruralidad, que es consustancial al peso del entorno, mayor al de la ciudad.

$\mathrm{Si}$ reducimos la escala, a un nivel micro, con foco en el núcleo urbano en torno a la plaza, la imagen cambia a las construcciones particulares como el Templo Parroquial y el Edificio de la Gobernación de Los Andes.

En la escala micro, las esquinas aparecen como preponderantes junto a la imagen del comercio. Calle Esmeralda, por la importancia social e institucional de sus edificios y espacios públicos y su relevancia urbana y arquitectónica, correlativo a los resultados del análisistopológico, escapturadaenlamayorpartedelasfotografíascompartidas(Fig. 13 al15).

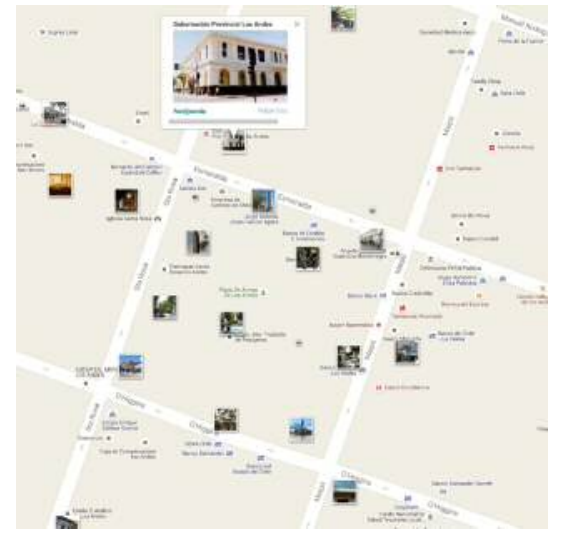

Fig. 14. Escala micro en Google Maps, con foco en Plaza de Los Andes.

Todas las imágenes consultadas en el mes de Noviembre de 2016 una prueba de concepto, por tanto de manera manual y muy básica. Las nuevas herramientas y posibilidades de software están cambiando día a día esta realidad. La revisión de los nuevos medios, cómo se comparte la información de los turistas sobre los destinos visitados, abre una nueva puerta a este tipo de estudios, donde las imágenes no solo se encuentran en grandes cantidades y georreferenciadas, sino que además existe la posibilidad de automatizar la lectura visual de ciertos elementos para reconocer patrones a todas las escalas. Un estudio de este tipo se aplica a la ciudad de Paris en base a las imágenes georreferenciadas de google Street view y con aplicación de software con el fin de detectar patrones en las fachadas de París y la hacían reconocible en su totalidad. (Doersch, Singh, Gupta, Sivic, \& Efros, 2012). 
En el caso de la esquina de Esmeralda con Santa Rosa, aun cuando no obtiene los valores más altos de inteligibilidad de las cuatro esquinas de la plaza, se encuentra reforzada en su imagen por los hitos visuales tanto de relevancia de fachada como la del edificio de la Gobernación y el hito de altura que representa la torre de la Iglesia.

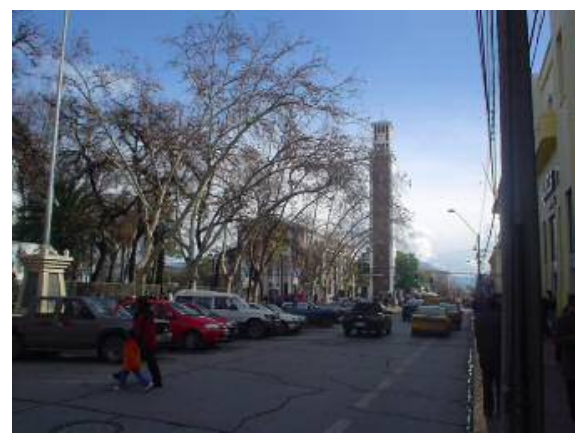

Fig. 15. Templo Iglesia Parroquial hacia desde acera norte de Esmeralda.

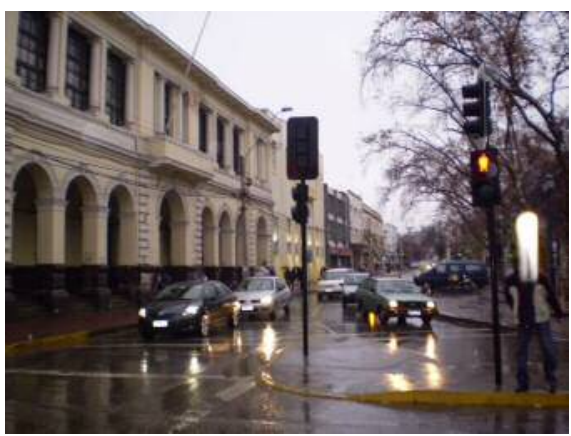

Fig. 16.- Gobernación Provincial.

En los análisis topológicos de los planos que se describieron más arriba, el núcleo urbano central, adquiere un gran nivel de inteligibilidad, que coincide con la estructura cuadricular, donde las calles que circundan la Plaza, Esmeralda y Maipú, y los ejes exteriores que contienen el damero, poseen gran relevancia.

Se reconoce en la Calle Esmeralda, un eje vial de gran importancia en el desarrollo histórico de la ciudad, generando una localización edilicia que potencia un imaginario y captura de fotografías sobre su emplazamiento, sobre todo en su conexión con la plaza (principal espacio público del área central). A su vez Maipú, en el contexto de la expansión sur de la ciudad, adquiere gran potencia en la conectividad e integración, al conecta el núcleo central con el sur de la ciudad, y con la comuna de San Esteban.

Los ejes exteriores que contienen el damero fundacional, Av. Argentina (norte), Av. Santa Teresa (poniente) y, Av. Chacabuco (sur) aparecen con valores destacados. Estas avenidas, en relación a la expansión de la ciudad desde su damero fundacional, se convierten en ejes de circulación en doble sentido, lo que aumenta su flujo y, por lo tanto, de su visualidad.

Estas características que alcanza la ciudad en el análisis topológico de los planos, se ve correlacionada con la geolocalización de las fotografías compartidas en pano ramio $^{4}$. En la Fig 14, se pueden observar los puntos que señalan la ubicación donde los usuarios han tomados sus imágenes y las han localizado en Google maps.

4 No obstante también aparecen concentraciones de fotografías en otros lugares de la ciudad, estos dicen relación con otras dimensiones, como la carretera internacional o áreas naturales, que no están graficados en los tres planos analizados. 
El núcleo central, las avenidas de la Plaza y los ejes exteriores del damero, son las vías depositarias de la mayor cantidad de información (en el espacio urbano).

El análisis topológico de los planos, que es un análisis computacional en abstractico de la configuración de la planta de la ciudad, en este caso, se ve graficado por la experiencia social de los turistas y visitantes (en menor medida de los habitantes locales). La ciudad de Los Andes, por su estratégica posición en el camino internacional hacia Argentina, y su corta distancia de núcleos urbanos mayores (Santiago y Gran Valparaíso) recibe un flujo constante de turistas y visitantes, que recorren sus principales avenidas, tanto por conectividad, como por integración.

Estos "foráneos", buscan materializarla su experiencia social y visual, tomando fotografías y compartiéndolas a través de distintos soportes, lo que está siendo estudiado últimamente en diversos destinos turísticos (Donaire \& Galí, 2011; Manosso \& Gándara, 2016). En nuestro caso, Panoramio, como hemos visto, permite que la experiencia y la imagen puedan ser georreferenciadas en los espacios donde se obtuvieron y, ser socializadas para ser vistas por otros. Es una forma de explicitar que se estuvo en un lugar. Dicho lugar, según los esquemas del análisis topológico de la trama y por la historia misma de la ciudad, permite indicar ciertas lógicas de uso y recorridos que tienen más probabilidad de ser fotografiados en una ciudad. En Los Andes, que no posee grandes íconos urbanos que motiven un recorrido turístico reconocible y pre-establecido, la inteligibilidad del espacio urbano, sobretodo de su núcleo central, se vuelve así en una configuración que lleva al visitante o al turista, por un conjunto de vías e íconos que se le van apareciendo y que se resuelve fotografiar. Esmeralda, como las avenidas que contienen el damero, se vuelven por lo tanto focos del lente de aquellos que quieren dejar huella de su paso por esta ciudad de provinciaenelcaminointernacional.Estasituaciónabrevariadasperspectivasparaelturismo.

\section{RUTA TURÍSTICA}

Por definición de la OMT, el turismo urbano está compuesto de visitas a centros urbanos con el fin principal de conocer, visitar o revisitar lugares de interés dentro de estos. Pudiendo ser espacios abiertos o construcciones, oferta comercial o cultural. Sin embargo, no se hace alusión a la manera en que estos recursos se enlazan entre sí, en otras palabras, la definición de la OMT no repara en la trama de estos centros urbanos como atractivo de primer o segundo orden. En términos topológicos podemos entender que las rutas turísticas se han entendido como conectores de atractivos y recursos, pero no como rutas que dejan ver otros recursos no directamente visibles como lo son la trama y las transformaciones de la ciudad en base a estas mismas tramas. Se piensa que esto se debe a que no se han considerado herramientas que permitan visualizar cuantificar y cualificar estas tramas como recursos para el turismo urbano, menos aún su relación con 
las imágenes compartidas que son generadas bajo las lógicas inteligibles de estas tramas.

En un principio el concepto de itinerario relacionado con el transporte específicamente ferroviario-yqueluegoampliara su definiciónpasándoseallamarruta-era siempreuntrazado y un recorrido por un espacio físico geográfico, no es sino hasta la creación de los itinerarios CulturalesporelConsejodeEuropa ${ }^{5}$ enlosañosochentadelsigloXXqueesteconceptoseamplía para abarcarademás construcciones culturales inmateriales enlazadas a estos recorridos.

Como concepto, las rutas turísticas en general se han definido como un corredor o camino utilizado por turistas itinerantes que se trasladan por vía terrestre entre dos destinos turísticos, reparando en los atractivos que complementan el trayecto (Pardo Tagle, 2014). Un concepto actualizado reconoce la oferta turística local patrimonial, definiéndose como “(...) un itinerario o recorrido temático propio de una comunidad o área geográfica, que permite el conocimiento de sus valores y atractivos más particulares, capaz de atraer visitantes y motivar su desplazamiento a lo largo de ella, visitando atractivos, realizando actividades y utilizando los servicios que han sido habilitados con ese objeto." (Pardo Tagle, 2014).

Dos condiciones que debe tener toda ruta turística es que debe estar circunscrita a un espacio geográfico determinado en conjunto a una unidad cultural reconocible. El damero fundacional de Los Andes cumple con estas. En conjunto a estas condiciones, la ruta debe conectar los principales recursos turísticos.

Con respecto a los usuarios o tipos de turistas que se apunta nos basamos en la definición que hace (Caro et al., 2015) que distingue entre cinco tipos de turista cultural en función de diversos aspectos motivacionales; el turista completo, el turista visitante, el turista descubridor, el turista casual y el turista accidental. Dentro de estos tipos de turista -sobre todos en los tres últimos- existe una gran influencia de las posibilidades que entrega la lectura de las lógicas de uso de los espacios en base a sus características topológicas determinadas por un trazado urbano en particular. Ya que justamente es este tipo de estudios los que nos entregan las claves para entender las lógicas de uso y preferencia de recorridos y lugares que permitirán un enfoque más preciso y local de los valores culturales de interés turístico de un centro urbano que aún no se ha puesto en valor como el caso del de la ciudad de Los Andes.

5 Específicamente por el Instituto Europeo de rutas culturales. La primera ruta que obtuvo el título de Ruta Cultural Europea fue la del Camino de Santiago de Compostela en España en 1987. Estas rutas apuntan a ser más que solo rutas turísticas, sino que según el Consejo de Europa buscan el enriquecimiento mutuo y el intercambio destacando el valor inmaterial cultural de los sitios que las componen. («Presentación - Patrimonio Europeo - Ministerio de Educación, Cultura y Deporte», s. f.) 


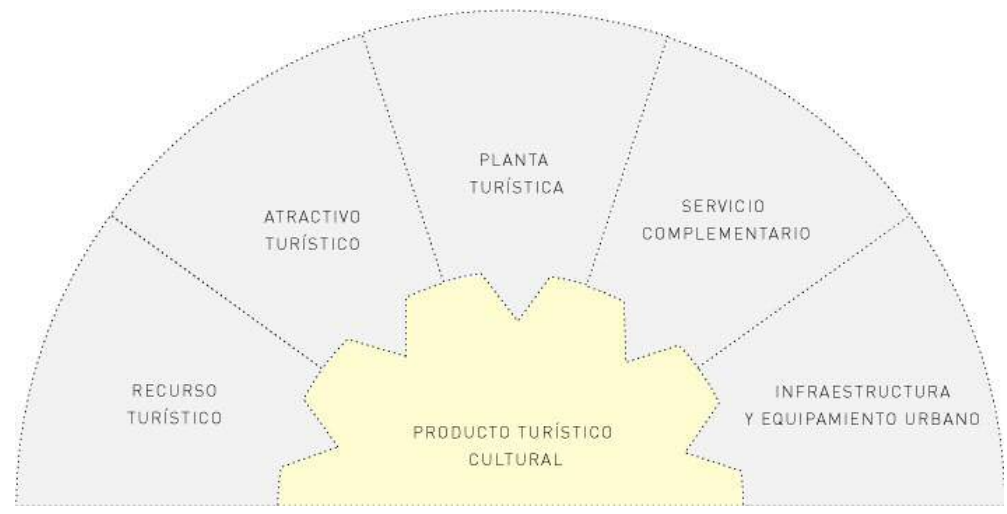

Fig. 17. Esquema de los componentes de un producto turístico cultural según la definición entregada con el Consejo Nacional de la Cultura y las Artes. Fuente: (Pardo Tagle, 2014). El análisis topologico previo influye en la definición de todos los componentes pero desde la demanda y la configuración espacial de los sitios, no desde la oferta o la construcción de los mismos desde estudios de otro carácter.

\section{CONCLUSIONES}

El análisis topológico y su correlación urbana y visual, nos muestran que existen oportunidades desaprovechadas para el turismo urbano en la ciudad de Los Andes en relación a sus ejes de conectividad e inteligibilidad.

La ciudad fundacional tiene un potencial desaprovechado como atractivo turístico e identitario al no considerar las características topológicas (configuracionales y visuales) que derivan en una tendencia de uso y, por tanto, en la construcción de una imagen reconocible y atractiva que además se encuentra sustentada por un rico relato histórico que podría ser dado a conocer en una ruta adecuada a las características de esta misma imagen topológica de ciudad.

Las tramas ortogonales como la del damero fundacional de Los Andes generan y bloquean aperturas visuales. La plaza fundacional se mantiene como el único punto que permite aperturas visuales multidireccionales, dando una importancia visual de alto contraste en las fachadas que enfrentan el espacio central, por sobre todo sus esquinas vinculadas a Esmeralda, de gran valor arquitectónico-patrimonial. Por otro lado, las calles que conectan este espacio central tienen una coincidencia de uso, contraste que propicia la oferta comercial por tendencia de uso. 
La Zona Típica del Centro Histórico de Los Andes, con todas las potencialidades patrimoniales que posee, no está relevada como lugar de valor, donde la visualidad de la fachada urbano-arquitectónica se proteja como un bien. Hoy día, la calidad arquitectónica y urbana del conjunto aparece descontextualizada, obstruida y manchada, por una intensa contaminación visual, proveniente de un cableado aéreo denso e inútil, y una gran cantidad de diferentes letreros desproporcionados e inconexos. Los valores arquitectónicos de la Zona Típica, no pueden leerse en su integración en el conjunto urbano, y aparece una imagen discordante y discontinua.

Estotampocoayudaala consolidación del centrohistórico como imagen cultural dentrodelas posibilidadesdesutrazado. Estefactorsedeterminaespecialmenteporlapreponderanciaenla planificación que ha tenido el trasporte motorizado particular, de manera inexplicable desde la perspectiva de uso, ya que el centro de la ciudad presenta distancias y escala peatonal. Ergo, la peatonalización del centro, o al menos parte de él y la conversión de las calles con los valores más altos de conectividad e integración (sobre todo aquellas asociadas a la zona típica) ayudarían a mejorar notablemente el atractivo urbano de la ciudad al dotarla de un imaginario, cuantitativa y cualitativamente, superior.

Como ya se ha expuesto, la situación más preocupante nos deja ver el análisis visual ya que el encuentro de isovistas es comparativamente en la zona de encuentro entre las principales avenidas exteriores del centro fundacional (Santa Teresa Argentina). Este importante nodo vial, es también uno visual al abrir el espacio a varios puntos de vistas, sin embargo, dentro del contexto está deteriorado y resulta hostil por el profuso y caótico tránsito vehicular (Fig. 14). Con esto se deteriora gran parte de la imagen meso y macro de la ciudad (la micro se encuentra cubierta por la calle esmeralda, la zona típica y la plaza). Es de carácter urgente revitalizar este nodo, con algún hito urbano relevante no solo para los alrededores sino para la ciudad también.

Mientras en el vértice sur-poniente del damero se produce otro nodo asociado a las nuevas construcciones habitacionales en altura y al comercio masivo del centro comercial (que como sabemos es alienante en su concepto). 


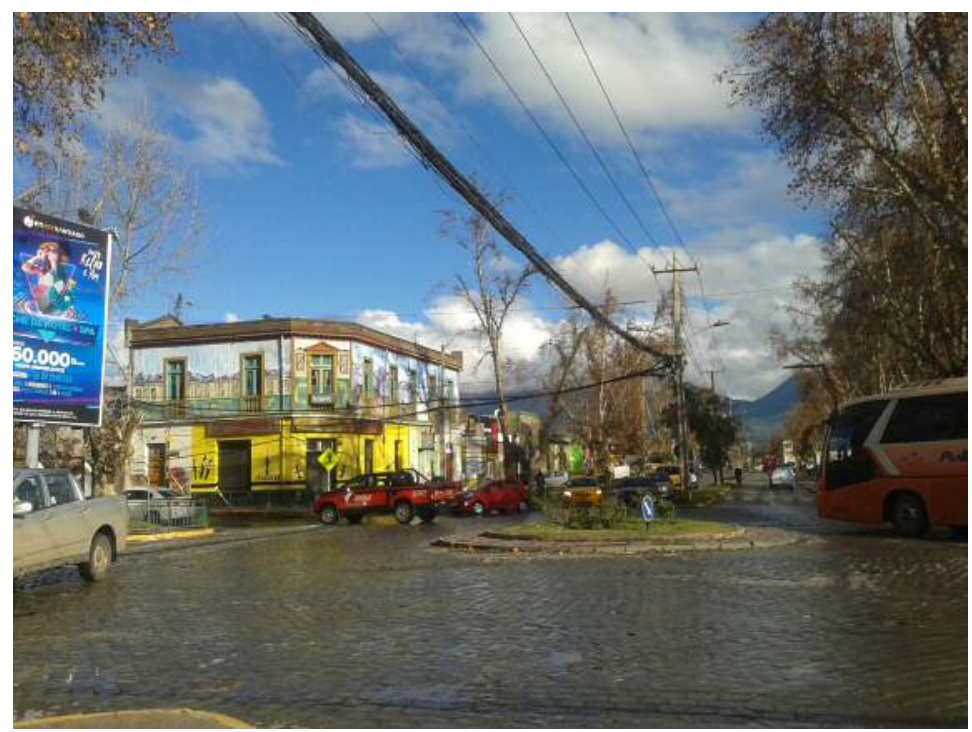

Fig. 18. Los Andes, 2016. Rotonda en el encuentro de las Avenida Santa Teresa (Norte-Sur) y Argentina (Oriente - Poniente). Según los resultados del análisis de la configuración espacial en las representaciones planimétricas, se trata del espacio más visible para los traslados a escalas intermedias y macro. Crédito Fotografía: Abel Cortez Ahumada.

Con todo, ante una ciudad difusa por su expansión desregulada en el tiempo, el centro urbano adquiere un mayor valor urbano patrimonial debido a su inmutabilidad estructural. Se hace un centro recorrible, entendible, con mayores grados de inteligibilidad comparativa. Cuestiones que se potencian por su escala peatonal.

Estas condiciones entregan una oportunidad para construir un atractivo turístico de la mano de la imagen arquitectónica y urbana del Centro histórico de Los Andes, una experiencia recorrible peatonalmente, un espacio para el conocimiento de una ciudad y de un trecho urbano de gran valor.

Eventualmente y a modo de ejemplo, unas rutas propuestas como las de la Fig. 16, utilizan algunas de las características del trazado de la ciudad de Los Andes -topológicas, físicas y visuales- así como sus espacios y construcciones que hemos reconocido en los diferentes análisis. Teniendo esta base el siguiente paso sería evaluar si contamos con los componentes necesarios para transformar estas rutas y el centro urbano junto a su zona típica en un producto turístico cultural según lo que estable el CNCA (fig. 14). 
El análisis topológico previo influye en la definición de todos los componentes, pero desde la demanda y la configuración espacial de los sitios, pudiendo complementarse desde la oferta (si es que existe) o la construcción de los mismos desde estudios de otro carácter.

\section{6.- BIBLIOGRAFÍA}

Chueca Goitia, Fernando. 1968. Breve historia del urbanismo. BOOK. Madrid: Alianza.

Cortez, Abel. 2012. Ensayos sobre Los Andes. Reflexiones sobre una ciudad de provincia. Municipalidad de Los Andes-GORE Valparaíso.

Caro, J. L., Luque, A., \& Zayas, B. (2015). Nuevas tecnologías para la interpretación y promoción de los recursos turísticos culturales. Revista de Turismo y Patrimonio cultural, 13, 931-945.

Doersch, C., Singh, S., Gupta, A., Sivic, J., \& Efros, A. a. (2012). What makes Paris look like Paris? ACM Transactions on Graphics, 31(4), 1-9. http://doi. org $/ 10.1145 / 2185520.2335452$

Hillier, B., \& Hanson, J. (1984). The Social logic of space. Cambridge etc.: Cambridge University Press.

Hsu, W., Lee, M. L., \& Zhang, J. (2002). Image mining: Trends and developments. Journal of Intelligent Information Systems, 19(1), 7-23. http://doi. org/10.1023/A:1015508302797

Klarqvist, B. (1993). A space syntax glossary. Nordisk Arkitekturforskning, 2, 11-12. Recuperado a partir de https://fenix.tecnico.ulisboa.pt/downloadFile/3779573909551/ glossarySS.pdf

Lynch, K. (1998). La Imagen de la ciudad. Barcelona : Gustavo Gili. Recuperado a partir de http://cataleg.upc.edu/record=b1145392 S1*cat

Márquez Rojas, J. (2013). Senderos en el bosque urbano. (E. ARQ, Ed.) (Primera Ed). Santiago de Chile.

Pardo Tagle, D. (2014). Estudio y Diseño de Rutas Temáticas de Valparaíso: Título I - Casiopea. Recuperado a partir de http://wiki.ead.pucv.cl/index.php/Estudio_y_Diseño_de_Rutas_Temáticas_de_Valparaíso:_Título_I

Presentación - Patrimonio Europeo - Ministerio de Educación, Cultura y Deporte. (s. f.). Recuperado a partir de http://www.mecd.gob.es/mecd/cultura-mecd/areas-cultura/ patrimonio/mc/patrimonioeur/itinerarios-culturales-europeos/presentacion.html Top 15 Most Popular Social Networking Sites (and 10 Apps!) - DreamGrow. (s. f.). Recuperado a partir de http://www.dreamgrow.com/top-15-most-popular-social-networking-sites/

Zhang, L., \& Chiradia, A. (2013). IN THE INTELLIGIBILITY MAZE OF SPACE SYNTAX : A space syntax analysis of toy models, mazes and labyrinths. 